\title{
Testis-expressed protein 33 is not essential for spermiogenesis and fertility in mice
}

\author{
MENGMENG XIA ${ }^{1,2^{*}}$, JING XIA $^{1,2^{*}}$, CHANGMIN NIU $^{1,2}$, YANAN ZHONG $^{1,2}$, \\ TINGTING GE ${ }^{1,2}$, YUE DING ${ }^{1,2}$ and YING ZHENG ${ }^{1,2}$ \\ ${ }^{1}$ Department of Histology and Embryology, School of Medicine, Yangzhou University; ${ }^{2}$ Jiangsu Key Laboratory of \\ Experimental and Translational Noncoding RNA Research, Yangzhou, Jiangsu 225001, P.R. China
}

Received May 20, 2020; Accepted November 11, 2020

DOI: $10.3892 / \mathrm{mmr} .2021 .11956$

\begin{abstract}
Gene expression analyses have revealed that there are $>2,300$ testis-enriched genes in mice, and gene knockout models have shown that a number of them are responsible for male fertility. However, the functions of numerous genes have yet to be clarified. The aim of the present study was to identify the expression pattern of testis-expressed protein 33 (TEX33) in mice and explore the role of TEX33 in male reproduction. Reverse transcription-polymerase chain reaction and western blot assays were used to investigate the mRNA and protein levels of TEX33 in mouse testes during the first wave of spermatogenesis. Immunofluorescence analysis was also performed to identify the cellular and structural localization of TEX33 protein in the testes. Tex33 knockout mice were generated by CRISPR/Cas9 gene-editing. Histological analysis with hematoxylin and eosin or periodic acid-Schiff (PAS) staining, computer-assisted sperm analysis (CASA) and fertility testing, were also carried out to evaluate the effect of TEX33 on mouse spermiogenesis and male reproduction. The results showed that Tex33 mRNA and protein were exclusively expressed in mouse testes and were first detected on postnatal days 21-28 (spermiogenesis phase); their expression then remained into adulthood. Immunofluorescence analysis revealed that TEX33 protein was located in the spermatids and sperm within the seminiferous tubules of the mouse testes, and exhibited specific localization to the acrosome, flagellum and manchette during spermiogenesis. These results suggested that TEX33 may play a role in mouse spermiogen-
\end{abstract}

Correspondence to: Professor Ying Zheng, Department of Histology and Embryology, School of Medicine, Yangzhou University, 136 Jiangyang Middle Road, Yangzhou, Jiangsu 225001, P.R. China

E-mail: yzzkl@163.com

*Contributed equally

Key words: TEX33, acrosome, sperm flagellum, manchette, spermiogenesis, male reproduction esis. However, Tex33 knockout mice presented no detectable difference in testis-to-body weight ratios when compared with wild-type mice. PAS staining and CASA revealed that spermatogenesis and sperm quality were normal in mice lacking Tex33. In addition, fertility testing suggested that the Tex33 knockout mice had normal reproductive functions. In summary, the findings of the present study indicate that TEX33 is associated with spermiogenesis but is not essential for sperm development and male fertility.

\section{Introduction}

Male fertility relies on the continuous production of sperm through a complex developmental process termed spermatogenesis. This process involves the differentiation of spermatogonia into spermatocytes, the development of spermatocytes into round spermatids through two successive meiotic divisions and the final elongation of spermatids $(1,2)$. The process of spermatid elongation is also known as spermiogenesis and involves the differentiation of round spermatids into sperm via marked morphological changes. Spermiogenesis includes chromatin condensation, elongation of the nucleus, biogenesis of the acrosome, extension of the flagellum and removal of excess cytoplasm (3-5).

The acrosome is a unique cap-like organelle that is derived from the Golgi apparatus and gradually expands to cover the apical region of the sperm nucleus (6). Formation of the acrosome is one of the most readily detectable changes in the seminiferous tubules (7), and the process responsible for acrosomal development has been well characterized. First, proacrosomal granules originating from the trans-Golgi stacks assemble in the concave region of the nuclear surface and fuse with each other to form a single acrosomal granule. This subsequently enlarges and spreads to form a cap over the nucleus. Finally, the acrosome migrates over the surface of the sperm nucleus and forms its characteristic shape (8-10).

Microtubule structure plays an important role in spermiogenesis. For example, the manchette, a temporary microtubular structure, first appears in step- 8 spermatids but subsequently disappears as spermiogenesis enters steps 13 and 14 (2). During the elongation of spermatids, the manchette shapes the distal half of the head and facilitates the intracellular transport of proteins to the flagellum $(11,12)$. 
A previous study reported that $>2,300$ genes are expressed predominantly in mouse testes (13), and a number of them are identified as serving important roles in numerous events during spermiogenesis through gene-editing technology, such as the biogenesis of the acrosome, the morphology of the manchette and the assembly of the flagellum. For example, mice lacking autophagy related 7 , sirtuin 1 , serine-rich single-pass membrane protein 1, vacuolar protein sorting (Vps) $13 b$, Vps54 and sperm acrosome associated 1 exhibit abnormal round-headed sperm as a result of aberrant acrosome formation (8,9,14-16). Leucine-rich repeats and guanylate kinase domain containing isoform 1, serine/threonine kinase 22, katanin-like 2, sperm flagellar 2, hook microtubule tethering protein 1 and calcium and integrin binding family member 4 are essential for the correct formation of the manchette; deficiency in any of these genes can lead to abnormal elongation of the manchette and thus, a malformed head or flagellum $(11,12,17-20)$. In addition, the deletion of sperm associated antigen 16, kinesin light chain 3 , kinase suppressor of ras 2, testis-specific serine kinase 4 or genes of the septin (Sep) family (Sept2, Sept 4 and Sept12) causes alterations in the intra-flagellum structure and reduces sperm motility (21-25). Despite the crucial function of these genes in spermiogenesis, the localization and functional requirement of other genes requires further characterization.

Testis-expressed protein 33 (TEX33), also known as Ean57, 1700061J05Rik, cE81G9.2 and C22orf33, is evolutionarily conserved. Orthologs of this protein have been identified in a number of different species, including humans, mice, Norwegian rats, zebrafish and Rhesus monkeys. A previous bioinformatics analysis revealed that TEX33 was expressed abundantly in the testis and associated with the formation of cilia (26). Therefore, we hypothesized that TEX33 may be a testis-enriched or specific protein that localizes to the sperm flagellum and is potentially associated with spermiogenesis.

The aim of the present study was to investigate the function of TEX33 in mouse spermiogenesis and fertility using CRISPR/ Cas9 gene-editing. It is hoped that the results will enrich our understanding of the molecular networks underlying spermiogenesis and provide new insight into the genetics of male fertility.

\section{Materials and methods}

Animals. A total of three male C57BL/6N mice aged 10 weeks and two female C57BL/6N mice aged 8 weeks were purchased from Cyagen Biosciences, Inc. The CRISPR/Cas9 system was used to generate Tex33 knockout mice. Two guide RNAs (gRNAs) were designed using the E-CRISPR database (http://www.e-crisp.org/E-CRISP/ designcrispr.html) to target exons 2-4 of Tex33: gRNA1, TACCAGAATCATCTAGTCCCTGG (matching the forward strand of the gene) and gRNA2, GCTAGCCAAGG CCAACACCTGGG (matching the reverse strand of the gene). The two gRNAs and Cas9 NLS endonuclease (cat. no. M0646M; New England BioLabs, Inc.) were microinjected into the cytoplasm of fertilized eggs from C57BL/6N mice. These eggs were then implanted into the oviducts of pseudo-pregnant female mice. Founder mice were then crossed with C57BL/6N mice to generate $T e x 33^{+/}$offspring. Finally, Tex $33^{-/}$mice were obtained by breeding from the Tex $33^{+/-}$mice.
All mice were maintained under specific pathogen-free conditions with free access to standard mouse lab pellet food and water, and housed at $20-22^{\circ} \mathrm{C}$ and $50-70 \%$ humidity with a 12-h light/dark cycle. All animal experiments were approved by the Animal Ethics Committee of Yangzhou University.

Reverse transcription-polymerase chain reaction (RT-PCR). For RNA extraction, heart, brain, spleen, liver, lung, kidney and trachea were collected from adult wild-type mice $(n=3)$ and testes were harvested from wild-type mice at different spermatogenesis stages (postnatal days 7, 14, 21, 28, 35 and 56; $n=3$ each). Total RNAs were isolated on ice using TRIzol ${ }^{\circledR}$ reagent (Invitrogen; Thermo Fisher Scientific, Inc.) and then dissolved in RNase-free distilled water. The purity of the total RNAs was determined using ultraviolet spectrophotometry (Eppendorf) and agarose gel electrophoresis. Only RNA samples with a ratio of absorbance at 260 and $280 \mathrm{~nm}$ of $\geq 1.8$ were used for RT-PCR. For reverse transcription, $500 \mathrm{ng}$ total RNA in a final volume of $10 \mu \mathrm{l}$ was mixed with 5X PrimeScript RT Master Mix (Takara Bio, Inc.) and RNase-free distilled water. For cDNA synthesis, the mixture was incubated at $37^{\circ} \mathrm{C}$ for $15 \mathrm{~min}$, and then at $85^{\circ} \mathrm{C}$ for $15 \mathrm{sec}$. Tex 33 transcript variants were then amplified by PCR using the following primers: Tex33 transcript variant V1: 5'-GGTTCATTTGCCTTCTTC CC-3' (forward), 5'-TCCTTGTCGTTCGGGTGTG-3' (reverse); Tex33 transcript variant V2: 5'-ACCTGGGGAGA GCTGCTGCTCG-3' (forward), 5'-GTTGGTGGTAGAGGT GGAG-3' (reverse); Tex33 transcript variant V3: 5'-TGGGTCA GGAAGGAGTGTG-3' (forward), 5'-GTTGGTGGTAG AGGTGGAG-3' (reverse). Glyceraldehyde 3-phosphate dehydrogenase $(G A P D H)$ was used as a positive control using the following primer sequences: 5'-GACGGCCGCATCTTCT TGT-3' (forward) and 5'-ACACCGACCTTCACCATTTT GT-3' (reverse). PCR was performed using a Taq DNA polymerase kit (cat. no. M1661S; Promega Corporation). Amplification conditions for Tex33 transcript variant V1, V2 and V3 were as follows: V1, initial denaturation step at $95^{\circ} \mathrm{C}$ for $5 \mathrm{~min}$ followed by 35 cycles of at $95^{\circ} \mathrm{C}$ for $30 \mathrm{sec}$, an annealing step at $60^{\circ} \mathrm{C}$ for $45 \mathrm{sec}$, an extension step at $72^{\circ} \mathrm{C}$ for $45 \mathrm{sec}$, and a final extension at $72^{\circ} \mathrm{C}$ for $10 \mathrm{~min}$; V2, initial denaturation at $95^{\circ} \mathrm{C}$ for $5 \mathrm{~min}$, followed by 35 cycles at $95^{\circ} \mathrm{C}$ for $30 \mathrm{sec}, 58^{\circ} \mathrm{C}$ for $30 \mathrm{sec}, 72^{\circ} \mathrm{C}$ for $45 \mathrm{sec}$, and elongation at $72^{\circ} \mathrm{C}$ for $10 \mathrm{~min}$; V3, an initial denaturation step of $5 \mathrm{~min}$ at $95^{\circ} \mathrm{C}$, followed by 35 cycles $95^{\circ} \mathrm{C}$ for $30 \mathrm{sec}, 52^{\circ} \mathrm{C}$ for $30 \mathrm{sec}$, $72^{\circ} \mathrm{C}$ for $45 \mathrm{sec}$, ended by a final elongation at $72^{\circ} \mathrm{C}$ for $10 \mathrm{~min}$. PCR protocol for GAPDH included a 5 min denaturation step at $95^{\circ} \mathrm{C}$ followed by 35 cycles of $50 \mathrm{sec}$ at $95^{\circ} \mathrm{C}, 1 \mathrm{~min}$ annealing step at $55^{\circ} \mathrm{C}$ and $1 \mathrm{~min}$ extension at $72^{\circ} \mathrm{C}$ and a final elongation at $72^{\circ} \mathrm{C}$ for $10 \mathrm{~min}$. PCR products were electrophoresed on $1.2 \%$ agarose gels using $1 \mathrm{X}$ Tris/Borate/EDTA buffer (TBE). Gels were stained with SYBR Safe ${ }^{\mathrm{TM}}$ (Thermo Fisher Scientific, Inc.) and the bands visualized using a gel imaging system (Tanon Science and Technology Co., Ltd.).

Synthesis of an anti-TEX33 antibody. PCR was used to amplify the open reading fragment (ORF) of Tex33 transcript variant V2 (encoding 266 amino acids), which represents the predominant transcript according to the GenBank database and shares the same ORF as V1. The following primers were used: 5'-GGGAATTCATGGAGCTGAGCCACCGAC-3' (forward) 
and 5'-GGAAGCTTGCTTGGCCTTGGATCTGCTC-3' (reverse). The PCR product was purified with a DNA gel extraction kit (Corning, Inc.), sequenced by next generation sequencing (BGI Group) and finally subcloned into a pET-30a (+) vector (Novagen; Merck KGaA). After induction with isopropyl $\beta$-D-thiogalactoside for $12-14 \mathrm{~h}$ at $37^{\circ} \mathrm{C}$, the prokaryotic protein samples were analyzed by electrophoresis on $10 \%$ sodium dodecyl sulfate (SDS) polyacrylamide gels using Coomassie Brilliant Blue solution. The TEX33 prokaryotic protein was successfully expressed in Escherichia coli BL21 (DE3) plysS (Novagen; Merck KGaA). The resulting His-tag fusion protein was purified using Ni-NTA affinity resin (RuiXiang Bio Inc.) in accordance with the manufacturer's instructions. The concentration of the purified protein was determined using a bicinchoninic acid (BCA) kit (CWBio).

A total of 5 male New Zealand white rabbits ( $\sim 2 \mathrm{~kg}$ body weight) aged 10 weeks were used for animal immunization. They were purchased from Laboratory Animal Center of Shanghai Branch of Chinese Academy of Science and maintained in individual cages at $22^{\circ} \mathrm{C}, 42 \%$ humidity, with a 12-h light/dark cycle and free access to food and water. Purified protein $(0.75 \mathrm{mg} / \mathrm{ml})$ was mixed with an equal volume of Freund's adjuvant (Sigma-Aldrich; Merck KGaA) and $500 \mu \mathrm{l}$ purified protein/adjuvant mixture was subsequently injected into the backs of adult male rabbits at $0,2,4,6$ and 8 weeks. After the last immunization, blood was harvested from each rabbit and the serum was separated. The antibody titer from each rabbit was determined using an enzyme-linked immunosorbent assay (ELISA; Fig. S1A).

For ELISA, $5 \mu \mathrm{g} / \mathrm{ml}$ purified TEX33 prokaryotic protein was added to each well of a 96-well plate (Corning Inc.) and incubated at $4^{\circ} \mathrm{C}$ overnight. After washing with $0.05 \%$ Tween-20 solution in phosphate-buffered saline (PBS-T), each well was blocked with $1 \%$ bovine serum albumin (BSA); Beijing Solarbio Science \& Technology Co., Ltd.) for $1 \mathrm{~h}$ at room temperature. After washing, 1:10, 1:100, 1:1,000, $1: 10,000,1: 100,000$, and 1:1,000,000 dilutions of serum were added and the plate was incubated at $37^{\circ} \mathrm{C}$ for $1 \mathrm{~h}$. The wells were then washed thrice with PBS-T and incubated with goatanti-rabbit IgG-HRP secondary antibody (cat. no. ZB-2301; 1:2,500 dilution; OriGene Technologies, Inc.) at $37^{\circ} \mathrm{C}$ for $1 \mathrm{~h}$. TMB Two-Component Substrate solution (Beijing Solarbio Science \& Technology Co., Ltd.) was then added and allowed to react for $10 \mathrm{~min}$ at room temperature in the dark. The reaction was stopped with $1 \mathrm{mM}$ hydrochloric acid and the absorbance was measured at $450 \mathrm{~nm}$ using a Multiskan FC microplate reader (Thermo Fisher Scientific, Inc.). The specificity of the antibody was confirmed by western blot (Fig. S1B) and immunofluorescence analyses (Fig. S1C-F).

Western blot analysis. For protein extraction, heart, brain, spleen, liver, lung, kidney and trachea were collected from multiple tissues of adult wild-type mice $(n=3)$ and testes were harvested from wild-type mice at different spermatogenesis stages (postnatal days 7, 14, 21, 28, 35 and 56; $n=3$ each). Tissues were lysed in RIPA buffer (CWBio) on ice, followed by sonication on ice for $10 \mathrm{~min}$. After centrifugation at $14,000 \mathrm{x} \mathrm{g}$ for $10 \mathrm{~min}$ at $4^{\circ} \mathrm{C}$, the supernatants were collected. The protein concentration was determined using a BCA kit. Protein samples $(40 \mu \mathrm{g})$ were then separated on
$10 \%$ SDS-polyacrylamide gels and transferred onto polyvinylidene fluoride membranes (Millipore; Merck KGaA). Non-specific antibody binding was blocked using 5\% non-fat milk in Tris-buffered saline (TBS) for $1 \mathrm{~h}$ at room temperature. Membranes were then incubated at $4^{\circ} \mathrm{C}$ overnight with the following primary antibodies: TEX33 antibody (1:1,000 dilution; generated in the present study), GAPDH antibody (cat. no. CW0100M; 1:2,500 dilution; CWBio) and $\beta$-actin antibody (cat. no. ET1701-80; 1:2,500 dilution; HuaBio). After washing with $0.05 \%$ TBS-T, membranes were incubated with goat-anti-rabbit IgG-HRP secondary antibody (cat. no. ZB-2301; 1:2,500 dilution; OriGene Technologies, Inc.) for $1 \mathrm{~h}$ at room temperature. After washing three times with TBS-T, protein bands were visualized with enhanced chemiluminescence reagent (New Cell and Molecular Biotech Co., Ltd.) using an automatic chemiluminescence image analysis system (Tanon Science and Technology Co., Ltd.).

Immunofluorescence analysis. In order to analyze tissue sections by immunofluorescence, testicular samples were collected from the mice and fixed in $4 \%$ paraformaldehyde solution ( $\mathrm{pH} 7.0)$ for $24-48 \mathrm{~h}$ at $4^{\circ} \mathrm{C}$. The testicular samples were dehydrated in an ascending alcohol gradient, then cleared in chloroform overnight. The cleared samples were infiltrated in xylene, embedded in paraffin and cut into 4- $\mu \mathrm{m}$ sections. The sections were rehydrated in a descending alcohol gradient followed by antigen retrieval in $10 \mathrm{mM}$ sodium citrate (pH 6.0) at $100^{\circ} \mathrm{C}$ for $10 \mathrm{~min}$. After blocking with $1 \%$ BSA for $1 \mathrm{~h}$ at room temperature, the sections were incubated with primary antibodies at $4^{\circ} \mathrm{C}$ overnight. The following primary antibodies were used: TEX33 antibody (1:200 dilution; generated in this study) and mouse $\alpha$-tubulin antibody (cat. no. AC012; 1:100 dilution; ABclonal Biotech Co., Ltd.). After washing with PBS, sections were further incubated with Alexa Fluor 488-conjugated donkey-anti-mouse secondary antibody (cat. no. A32766TR; 1:1,000 dilution; Thermo Fisher Scientific, Inc.) and Alexa Fluor 555-conjugated donkey-antirabbit secondary antibody (cat. no. A-31572; 1:1,000 dilution; Thermo Fisher Scientific, Inc.) for $1 \mathrm{~h}$ at room temperature, and then counterstained with 4',6-diamidino-2-phenylindole (DAPI) dye (cat. no. C0060; 1:1,000 dilution; Beijing Solarbio Science \& Technology Co., Ltd.) for $10 \mathrm{~min}$ at room temperature. Fluorescence intensity was finally detected by confocal laser-scanning microscopy (Carl Zeiss AG).

In order to investigate sperm using immunocytochemistry, the cauda epididymis of each mouse was cut into small pieces to allow motile sperm to swim out. After filtration and centrifugation at $800 \mathrm{x}$ g for $15 \mathrm{~min}$ at room temperature, the sperm sample was rinsed with PBS, incubated in PBS at $37^{\circ} \mathrm{C}$ for $15 \mathrm{~min}$, smeared on slides and fixed with $4 \%$ paraformaldehyde solution for $30 \mathrm{~min}$ at room temperature. The slides were blocked with donkey serum (cat. no. SL050; 1:100 dilution; Beijing Solarbio Science \& Technology Co., Ltd.) at room temperature for $1 \mathrm{~h}$, and then incubated with anti-TEX33 primary antibody (1:100 dilution; generated in the present study) at $4^{\circ} \mathrm{C}$ overnight. This was followed by incubation with FITC-conjugated peanut agglutinin (PNA-FITC; cat. no. L7381; 1:50 dilution; Sigma-Aldrich; Merck KGaA) and Alexa Fluor 555 donkey-anti-rabbit secondary antibody (cat. no. A-31572; 1:1,000 dilution). After washing three times 
with PBS, the nuclei were stained with DAPI for $10 \mathrm{~min}$ at room temperature. Images were captured by confocal laserscanning microscopy.

Mouse genotyping. Mouse tail samples $(0.2-0.3 \mathrm{~cm})$ were obtained and lysed at $55^{\circ} \mathrm{C}$ overnight in lysis buffer containing $1 \mathrm{mM}$ Tris- $\mathrm{HCl}$ (pH 8.0), $1 \mathrm{mM} \mathrm{NaCl}, 1 \mathrm{mM}$ EDTA (pH 8.0), $0.5 \%$ SDS and $10 \mu \mathrm{g} / \mu$ l proteinase K (Sigma-Aldrich; Merck $\mathrm{KGaA}$ ). Genomic DNA was extracted from the lysate using phenol and chloroform (Beijing Solarbio Science \& Technology Co., Ltd.), precipitated with isopropanol (Sinopharm Chemical Reagent Co., Ltd.) and dissolved in distilled water at $60^{\circ} \mathrm{C}$. Subsequent PCR was performed using a Taq DNA polymerase kit (cat. no. M1661S; Promega Corporation) according to the manufacturer's instruction. Primers for genotyping were designed: 5'-CAGCCGATGCTTCTATGACAAC-3' (forward), 5'-TCCCACATTTTCCGCAGGTG-3' (reverse 1), 5'-TCTGGGCTCCGTAATGTCTG-3' (reverse 2). The PCR conditions were as follows: Denaturation at $94^{\circ} \mathrm{C}$ for $5 \mathrm{~min}$, followed by 35 cycles at $94^{\circ} \mathrm{C}$ for $50 \mathrm{sec}, 55^{\circ} \mathrm{C}$ for $1 \mathrm{~min}, 65^{\circ} \mathrm{C}$ for $50 \mathrm{sec}$, and a final extension at $65^{\circ} \mathrm{C}$ for $10 \mathrm{~min}$. PCR products were separated on $1.2 \%$ agarose gels by electrophoreses in $1 \mathrm{X}$ TBE buffer. The products were visualized using a gel imaging system (Tanon Science and Technology Co., Ltd.) after staining with SYBR Safe ${ }^{\mathrm{TM}}$ (Thermo Fisher Scientific, Inc.).

Histological analysis. Paraffin sections $(\sim 4 \mu \mathrm{m})$ fixed in Bouin's solution (including testes, cauda epididymides and ovaries) were used for both histological and morphological analyses. The sections were dewaxed with xylene, and then rehydrated with 100, 95, 90, 80 and 70\% alcohol for 2 min each. After washing with RNase-free distilled water, the sections were used for hematoxylin and eosin (H\&E) or periodic acid-schiff (PAS) staining.

For H\&E staining, the sections were first stained with hematoxylin (Beyotime Institute of Biotechnology) for $2 \mathrm{~min}$ at room temperature, followed by 6 dips in $1 \%$ hydrochloric alcohol and rinsing in RNase-free distilled water. The sections were then stained with eosin (Beyotime Institute of Biotechnology) for $3 \mathrm{sec}$ at room temperature, followed by dehydration in 70 , 90 and $100 \%$ alcohol for 1 min each. Finally, the sections were immersed in xylene for $5 \mathrm{~min}$. Images were visualized by light microscopy (Nikon-70i; Nikon Corporation).

For PAS staining, a Schiff's kit (cat. no. G1360; Beijing Solarbio Science \& Technology Co., Ltd.) was used in accordance with the manufacturer's protocols. In brief, the sections were pretreated with periodic acid for $5 \mathrm{~min}$ at room temperature, slowly rinsed in RNase-free distilled water and then stained with Schiff's solution for $10 \mathrm{~min}$ at room temperature in the dark. The nuclei were stained with hematoxylin for $5 \mathrm{~min}$ at room temperature, followed by 6 dips in $1 \%$ hydrochloric alcohol. After dehydration with 70, 90 and $100 \%$ graded alcohol, the sections were immersed twice in xylene for $10 \mathrm{~min}$ each. Images were captured using light microscopy (Nikon-70i).

Analysis of sperm motility and morphology. Cauda epididymides were collected and rinsed with RNase-free distilled water, followed by the incubation of swim-out sperm in $1 \mathrm{ml}$ warm human tubal fluid (Wisent Biotechnology) at $37^{\circ} \mathrm{C}$. The total sperm count was determined using a hemocytometer and sperm motility was determined with a computer-assisted sperm analysis system (CASA; Sperm Class Analyzer v. 4.0.0; Microptic S.L., Barcelona, Spain). The sperm deformity rate was studied using sperm smears and microscopy counting methods. Sperm smears were stained with H\&E and images were captured by light microscopy (Nikon-70i). More than 1,000 sperm were observed and counted from $\mathrm{Te} 333^{+/+}$and Tex $33^{-/-}$males ( $\mathrm{n}=3$ mice/group). The numbers of sperm showing normal and abnormal morphology were counted and analyzed.

Fertility testing. Tex $33^{+/+}$and Tex33 $3^{-/-}$male mice (10-12 weeks old) were continuously mated with $T e x 33^{+/+}$female mice (8-10 weeks old) with demonstrable fertilizing ability (at a ratio of 1:2) for 1 month. The Tex $33^{+/+}$female mice were changed once a week. Plugs and the numbers of pups born were recorded.

Statistical analysis. Sperm quality and average litter sizes are expressed as mean \pm standard error of mean and the Student's t-test was used to identify significant differences. Plugs and pregnancies were compared between Tex $33^{+/+}$and Tex $33^{-1-}$ mice using the Chi-squared test. $\mathrm{P}<0.05$ was considered to indicate a statistically significant result.

\section{Results}

Expression of Tex33 during spermatogenesis in mice. The GenBank database revealed that the mouse Tex33 gene is located in the E1 region of chromosome 15 and contains seven exons (Fig. 1A). There are three transcript variants: V1, V2 and V3 (Fig. 1B). V1 is the longest Tex33 transcript variant; it is 1,147 bp in size and lacks exon 3 as the result of alternative splicing events (Fig. 1B). V2 is the predominant transcript variant of the Tex33 gene according to GeneBank, and exhibits alternative splice sites in exon 1 and exon 3 , resulting in an additional exon and the deletion of exon 3 (Fig. 1B). Another transcript variant, V3, is the shortest variant and exhibits alternative splice sites in exons 1 and 2 (Fig. 1B). The translation of V1 and V2 begins from the same site in exon 2 and these two variants share one stop codon in exon 7; thus, they both encode the same isoform (isoform 1; Fig. 1C). However, V3, encoding isoform 2, translates from exon 4 and lacks a portion of the 5 ' coding region; this leads to a shorter $\mathrm{N}$-terminus compared with isoform 1 (Fig. 1C).

To examine the mRNA levels of Tex33 in vivo, specific primers were designed for the three transcript variants and the expression profiles of the three transcript variants were then determined by RT-PCR using cDNA samples synthesized from various adult mouse organs, including the heart, brain, spleen, liver, lung, kidney, trachea and testis. The results showed that all transcript variants were only detected in the testes (Fig. 1D). To investigate the levels of TEX33 protein in these tissues, a TEX33 antibody with high efficiency was generated as described in our previous study (27). Western blot analysis performed using the TEX33 antibody revealed that TEX33 was expressed exclusively in the testes, which is 


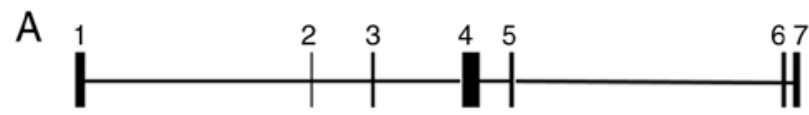

$\mathrm{B}$

\begin{tabular}{|c|c|c|c|c|c|c|}
\hline \multirow[b]{2}{*}{ Tex33 V1 } & \multicolumn{2}{|c|}{ NM_001163612.2 } & \multicolumn{3}{|c|}{1147 bp } & \\
\hline & 1 & 2 & 4 & 5 & 6 & 7 \\
\hline
\end{tabular}

NM_028522.1

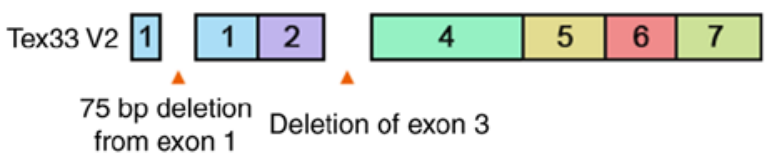

NM_001163613.1

$942 \mathrm{bp}$

\begin{tabular}{|l|l|l|l|l|l|}
\hline Tex33 V3 & 4 & 5 & 6 & 7 \\
\hline
\end{tabular}

Deletion of exon 1 and 2

D

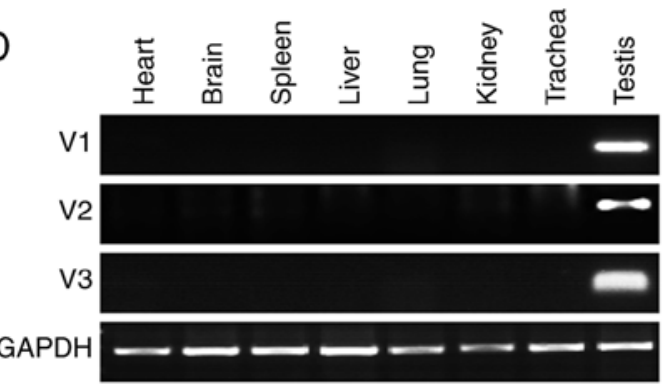

F

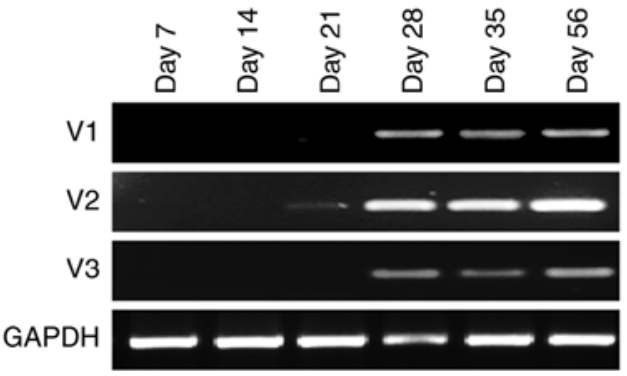

C
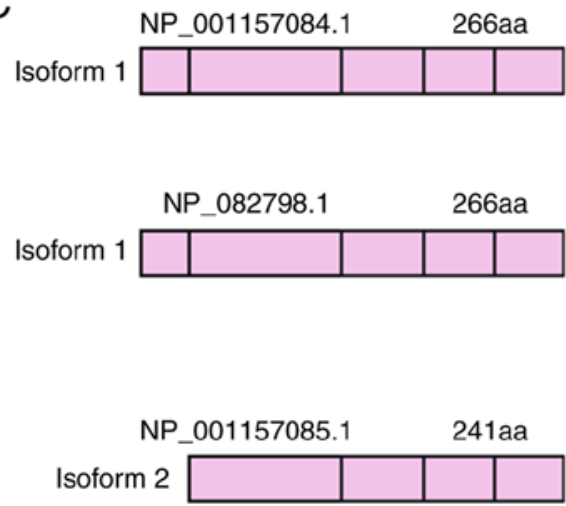
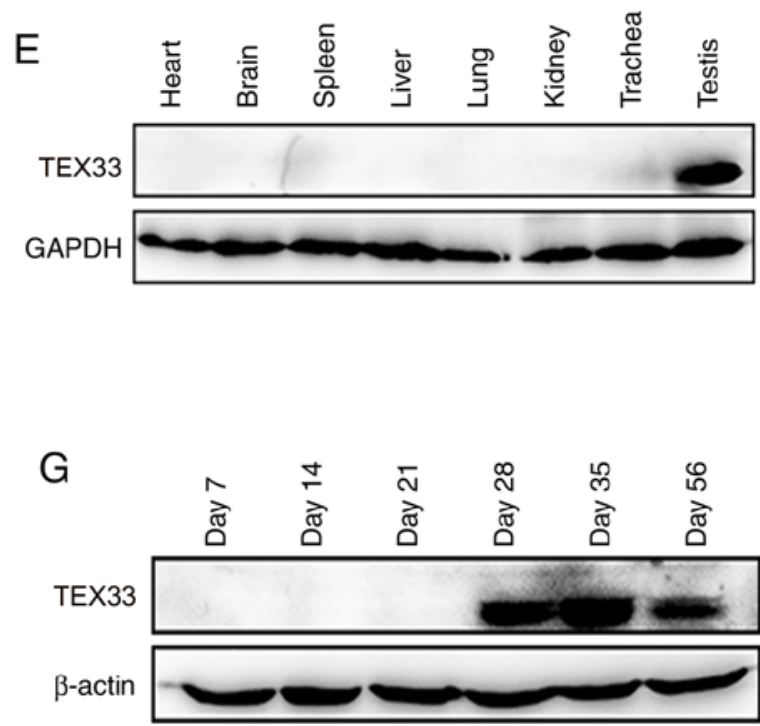

Figure 1. Characterization of mouse Tex33. (A) Analysis of the Tex33 gene in mice. The Tex33 gene consists of seven exons. (B) Tex33 transcript variants in mice. Deleted regions reveal alternate splicing events and different combinations of exons. Transcript variant V1 contains six exons, transcript variant V2 has seven exons and transcript variant V3 has five exons. (C) Two different isoforms are encoded by transcript variants V1, V2 and V3. (D) mRNA levels of Tex33 transcript variants in various mouse tissues were analyzed by RT-PCR. Transcript variant V1, 220 bp; transcript variant V2, 348 bp; transcript variant V3, 261 bp. (E) Expression of TEX33 protein in various mouse tissues, as determined by western blot analysis. (F) Expression of Tex33 transcript variants during the first wave of spermatogenesis, as determined by RT-PCR. (G) Expression of TEX33 protein during the first wave of spermatogenesis, as determined by western blot analysis. TEX33, testis-expressed protein 33; RT-PCR, reverse transcription-polymerase chain reaction.

consistent with the expression profiles of the transcript variants (Fig. 1E).

To determine the expression profile of Tex33 during the first wave of spermatogenesis, mouse testes were obtained at postnatal day 7 (containing only spermatogonia), day 14 (containing spermatogonia and spermatocytes), day 21 (in which round spermatids begin to appear), day 28 (in which spermatids begin to elongate), day 35 (around which time the first wave of spermatogenesis is completed) and day $56(3,28)$. The results of RT-PCR analysis suggested that V2 was expressed weakly from day 21 in the mouse testes, peaked at day 28 and was expressed into adult- hood, while V1 and V3 were expressed from day 28 and maintained peak expression levels into adulthood (Fig. 1F). Western blotting showed that TEX33 protein first presented on day 28 and maintained high expression levels into adulthood (Fig. 1G). The appearance of Tex33 transcript variants and proteins coincides with the spermiogenesis phase, during which time the appearance of round spermatids begins and spermiogenesis is initiated (28).

Immunofluorescence analysis demonstrated that TEX33 protein was localized in spermatids and testicular sperm within the seminiferous tubules (Fig. 2A). In spermatids, TEX33 was detected in Golgi-derived pro-acrosomal granules, 


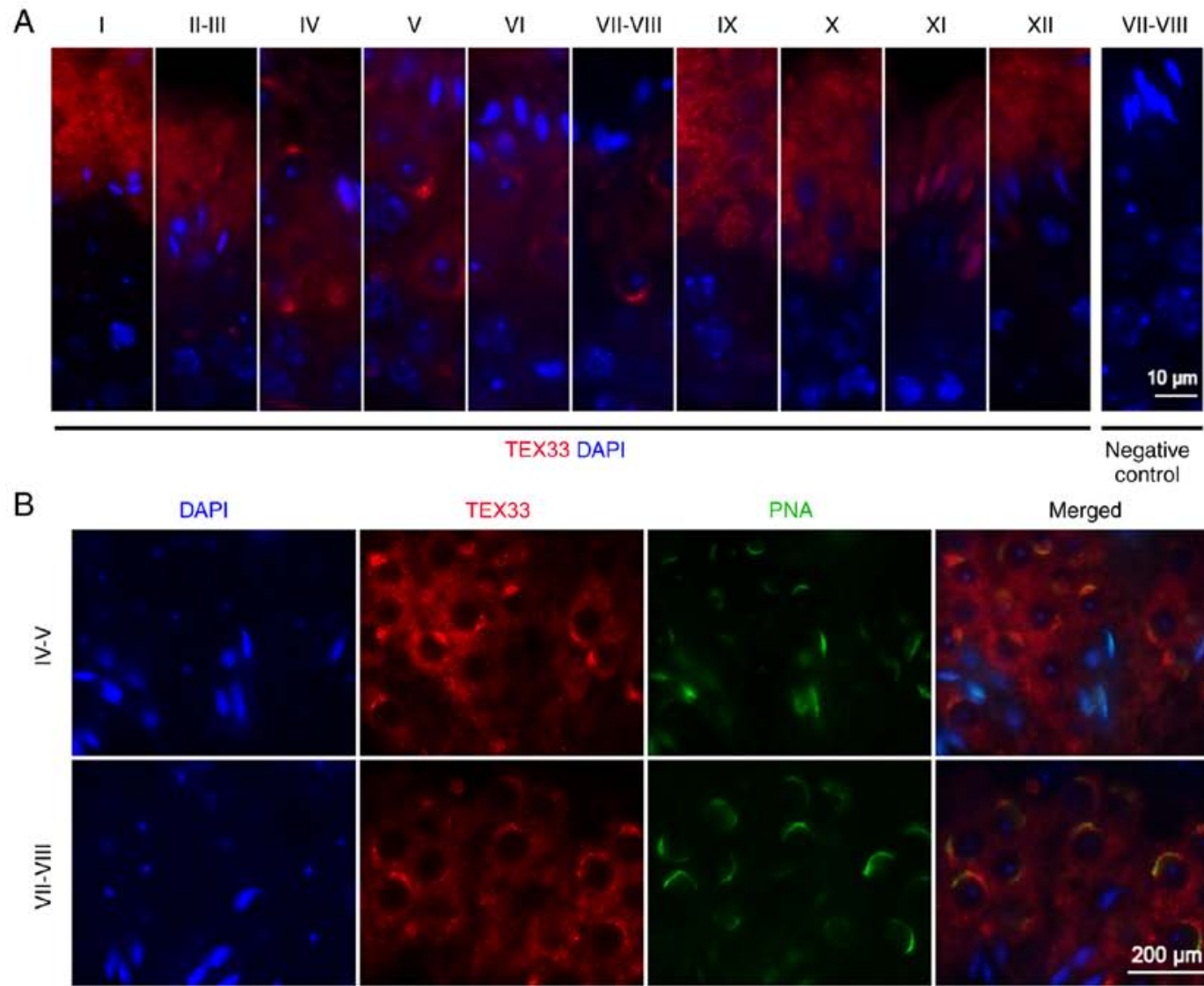

C

DAPI

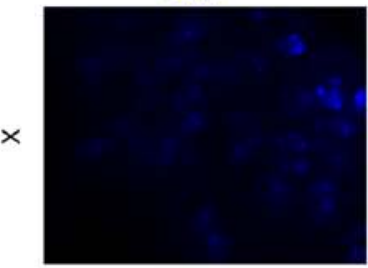

D

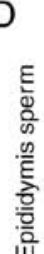

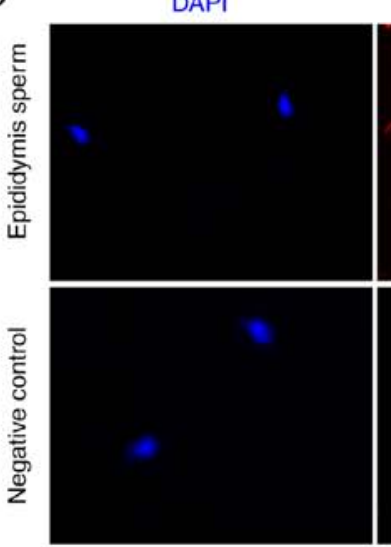

TEX33

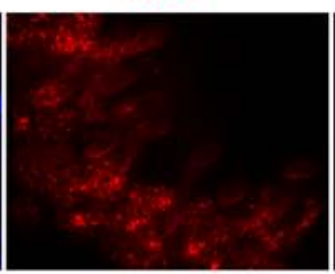

TEX33

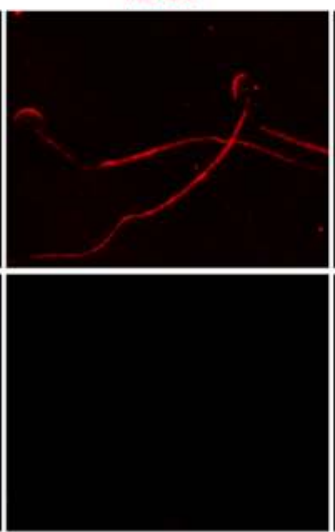

$\alpha$-tubulin

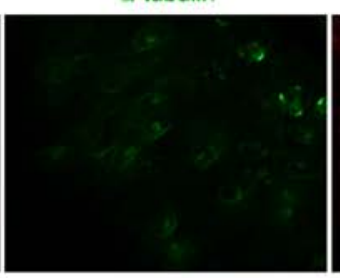

PNA

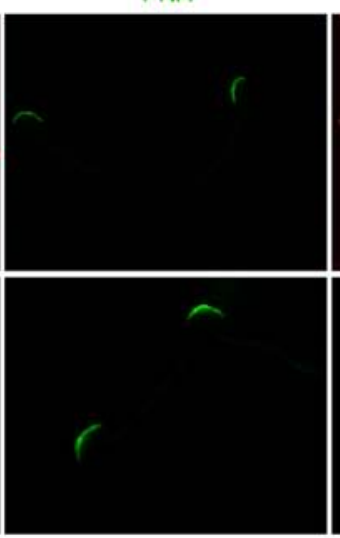

Merged

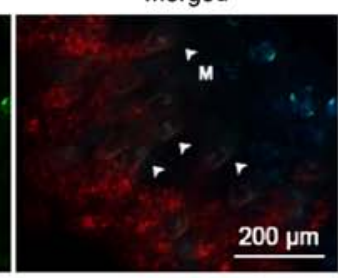

Merged

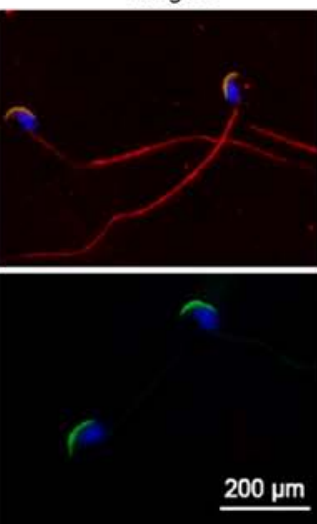

Figure 2. Localization of TEX33 during spermatogenesis. (A) Immunofluorescence staining of TEX33 in the seminiferous tubules during different stages of spermatogenic development (stages I-XII). (B) Co-immunofluorescence staining of TEX33 with PNA-FITC in the seminiferous tubules during different stages of spermatogenic development. (C) Co-immunofluorescence staining of TEX33 and $\alpha$-tubulin in elongating spermatids during spermatogenic stage X. (D) Co-immunofluorescence staining of TEX33 with PNA-FITC in sperm. TEX33, testis-expressed protein 33; PNA-FITC, FITC-conjugated peanut agglutinin; DAPI, 4',6-diamidino-2-phenylindole; M, manchette (indicated by arrowheads).

the cap-like acrosome and the fully formed acrosome from spermatogenic stages I to XII (Fig. 2A). It has been reported that the acrosome could bind many lectins in a variety of mammalian species $(29,30)$, such as peanut agglutinin (PNA), which reacts specifically with acrosomal sugar components and is widely used to visualize acrosomal formation (31-35). 


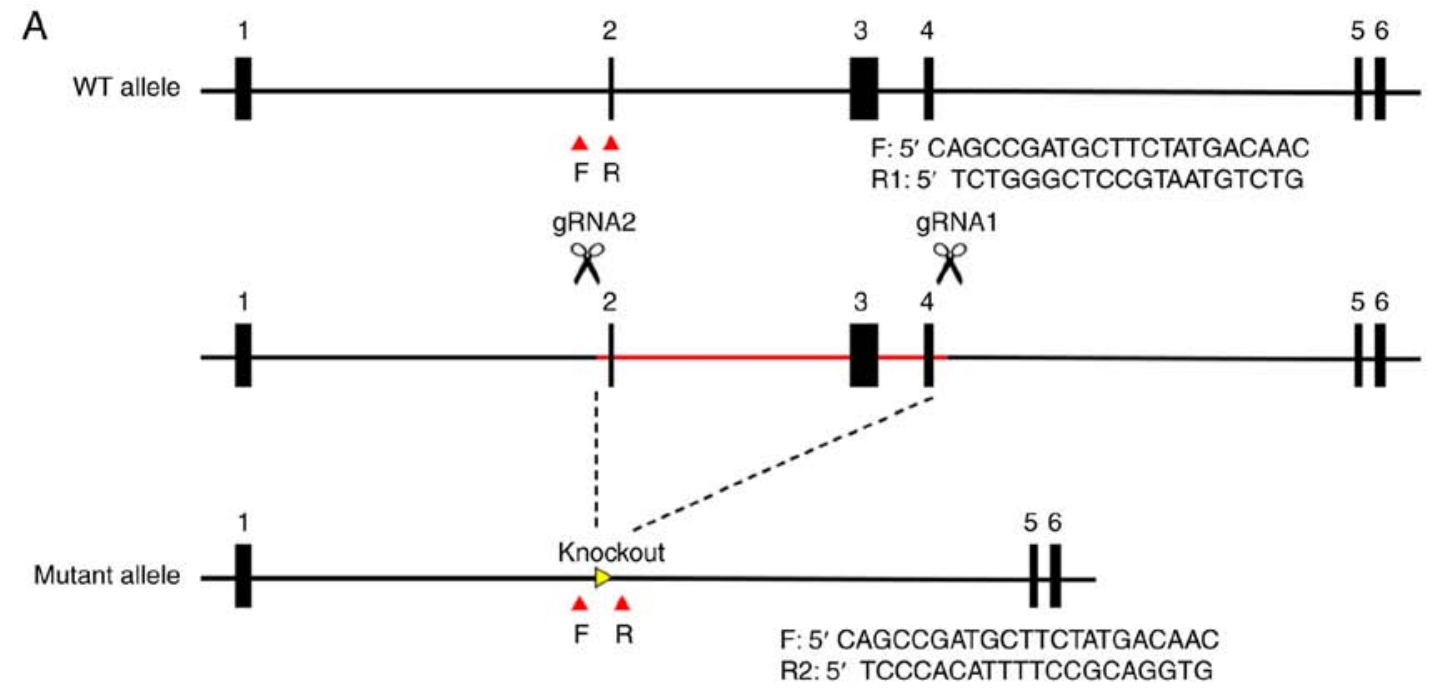

- Primers for genotyping $1 \mathrm{~kb}$
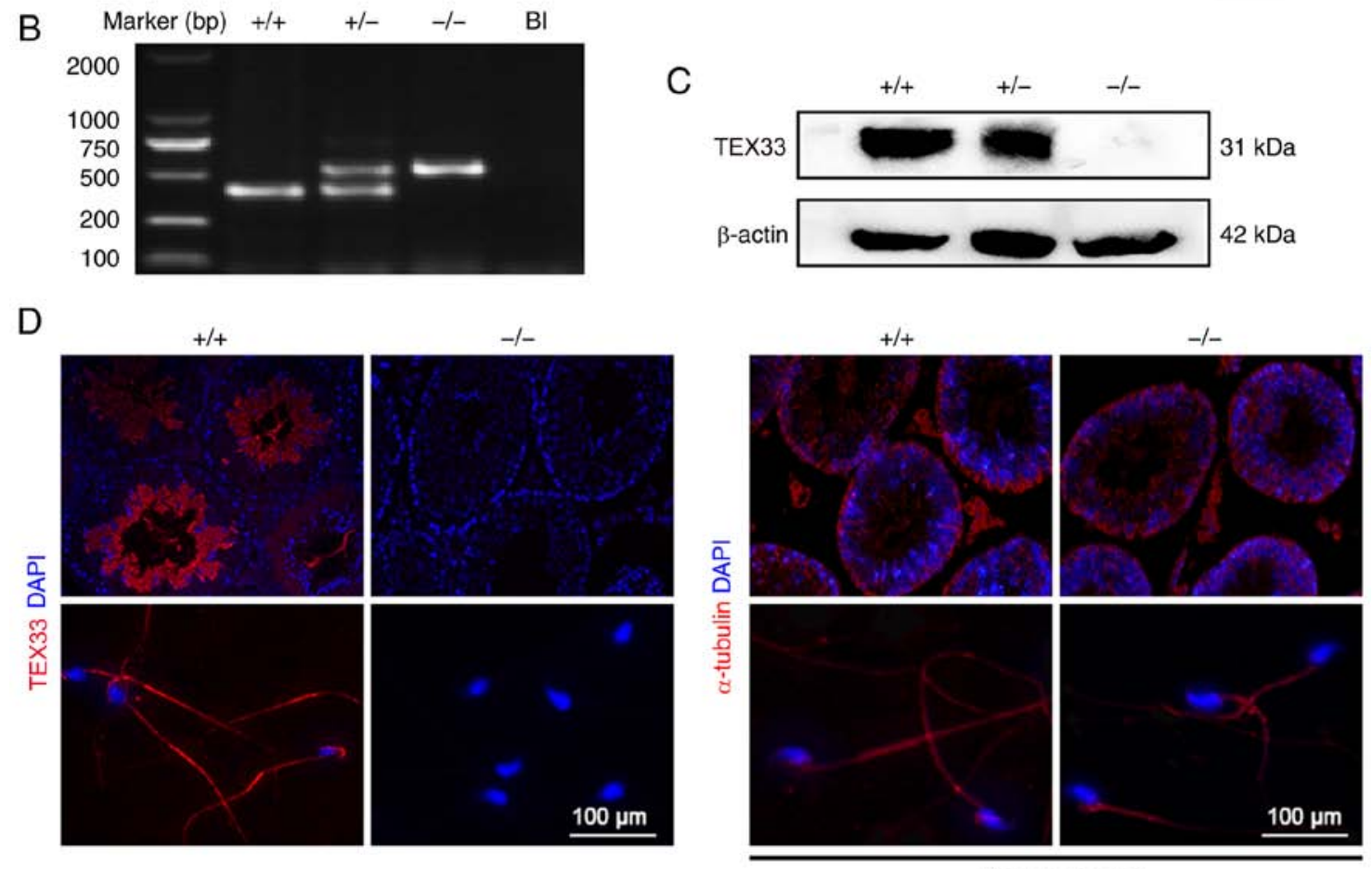

Positive control

Figure 3. Generation of Tex33 knockout mice. (A) Schematic representation of the deletion of Tex33 exons 2-4 via Cas9 microinjection. Primers were designed for genotyping. F targets intron 1, R1 targets exon 2 and R2 targets intron 4. (B) Genotyping of Tex33 offspring by PCR assay. (C) Comparison of TEX33 knockout efficiency between $T e x 33^{+/+}, \operatorname{Te} 333^{+/}$and $T e x 33^{-/}$mice by western blot analysis. (D) Detection of TEX33 expression in testes (upper panels) and sperm (lower panels) by immunofluorescence analysis. WT, wild-type; F, forward; R, reverse; gRNA, guide RNA; TEX33, testis-expressed protein 33; +/+,

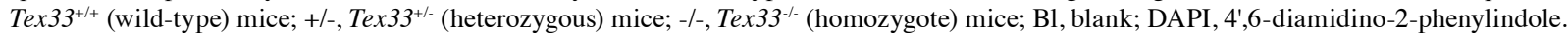

In the present study, TEX33 was co-localized with PNA on the acrosomes during different stages of spermatid development (Fig. 2B) and on mature acrosomes (Fig. 2D). TEX33 was also detected on the manchette of elongating spermatids (spermatogenic stage $\mathrm{X}$ ) via $\alpha$-tubulin co-labeling (Fig. 2C), as well as the sperm flagellum (Fig. 2D). These findings indicate that TEX33 may be involved in the formation of the acrosome, manchette and flagellum during spermiogenesis.

Deletion of Tex33 in mice. The initial data indicate that TEX33 is expressed at high levels in mouse testes. On the basis of this, the biological function of TEX33 during spermatogenesis was investigated. CRISPR/Cas9-mediated genome engineering was used to create Tex33 knockout mice. Exons 2, 3 and 4 were selected as the target sites. Cas 9 and gRNA were co-injected into fertilized eggs in order to delete exons 2-4 (Fig. 3A). Mice were then genotyped by PCR using specific primers (Fig. 3A and B). Western blot analysis was performed on testis samples to validate the efficiency of Tex33 removal. As shown in Fig.3C, TEX33 protein was present in the

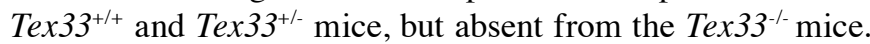
Furthermore, immunofluorescence analysis of the testis and 

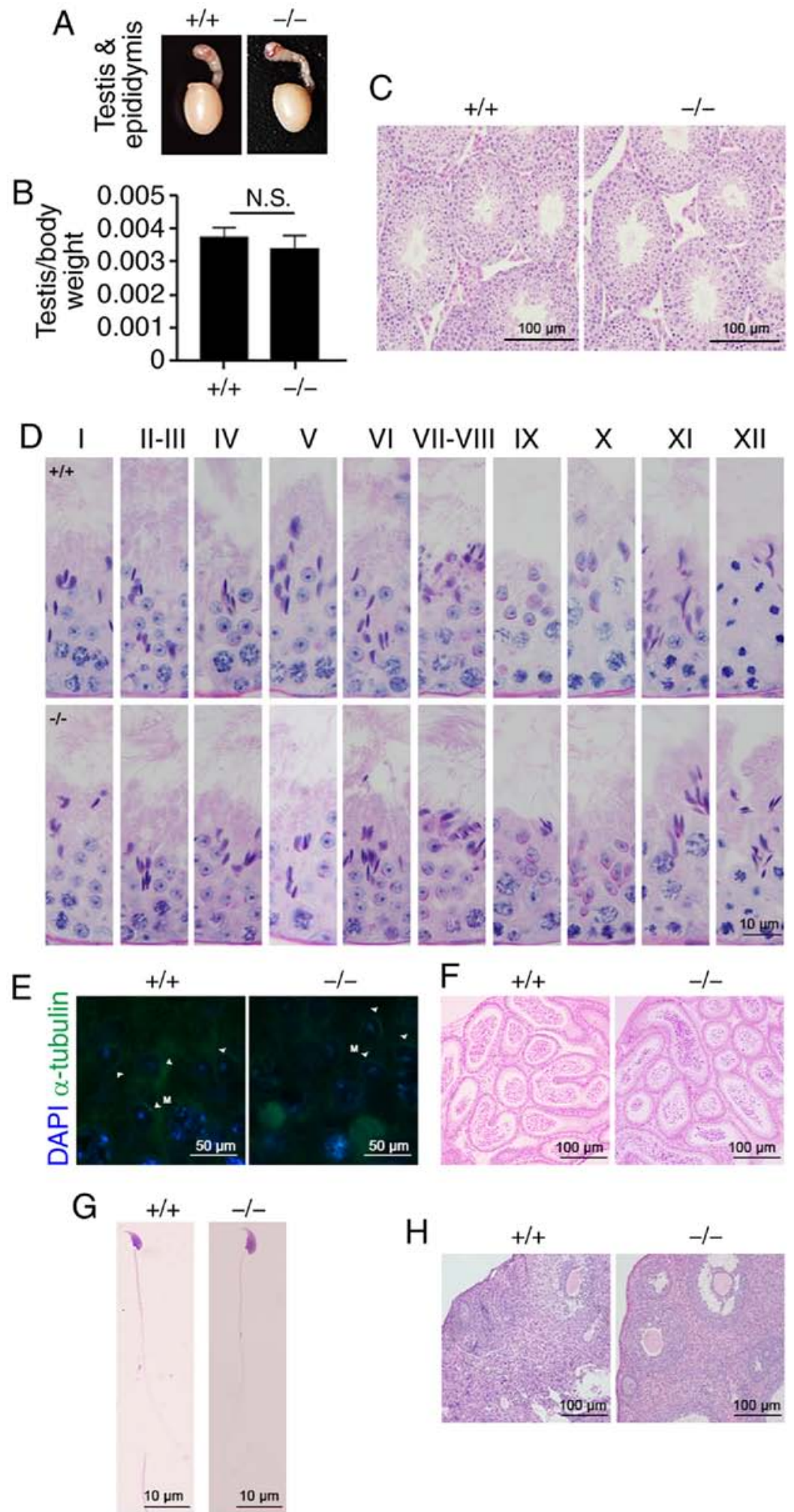

Figure 4. Phenotypic analysis of Tex33 knockout mice. (A) Testis and epididymis from Tex $33^{+/+}$and Tex $33^{-/}$males. Tissue samples were collected from 10-week-old male mice (n=5 per genotype). (B) Testis/body weight ratio of $T e x 33^{+/+}$and $T e x 33^{-/}$males. Values are expressed as mean \pm standard error of mean. (C) H\&E staining showing seminiferous tubules with normal histology in Tex $33^{+/+}$and Tex33 $3^{-/}$males. (D) Periodic acid-Schiff staining showing normal acrosome development and spermatogenesis in Tex $33^{+/+}$and Tex $33^{-/-}$males. (E) Co-immunofluorescence staining of TEX33 and $\alpha$-tubulin in elongating spermatids revealed normal manchette morphology in both $T e x 33^{+/+}$and $T e x 33^{-/}$males. H\&E staining of Tex $33^{+/+}$and Tex $33^{-/}$males showing normal (F) cauda epididymis and (G) sperm. (H) H\&E staining revealed normal ovarian morphology in Tex $33^{+/+}$and Tex $33^{-/-}$females. H\&E, hematoxylin and eosin; Tex33, testis-expressed protein 33; +/+, Tex33 $3^{+/+}$(wild-type) mice; -/-, Tex33\% (homozygote) mice; M, manchette (indicated by arrowheads); DAPI, 4',6-diamidino-2-phenylindole; N.S., not significant.

sperm confirmed that TEX33 expression was absent from the Tex33 $3^{-\digamma}$ mice (Fig. 3D).
Tex33 deletion does not affect spermatogenesis and fertility. To determine whether the deletion of Tex33 has an effect on 
Table I. Analysis of sperm quality in $T e x 33^{+/+}$and $T e x 33^{-/-}$male mice.

\begin{tabular}{lcccc}
\hline Genotype & Sperm count $\left(\mathrm{x} 10^{6} / \mathrm{ml}\right)$ & Total sperm motility $(\%)$ & Progressive motility $(\%)$ & Sperm deformation $(\%)$ \\
\hline$+/+(\mathrm{n}=3)$ & $9.02 \pm 0.46$ & $80.82 \pm 3.69$ & $57.59 \pm 5.06$ & $16.31 \pm 3.76$ \\
$-/-(\mathrm{n}=3)$ & $8.98 \pm 0.35$ & $77.96 \pm 4.51$ & $58.26 \pm 3.47$ & $18.12 \pm 4.08$ \\
P-value & 0.91 & 0.47 & 0.86 & 0.60 \\
\hline
\end{tabular}

Data are expressed as mean \pm standard error of the mean and were analyzed using Student's t-test. Tex33, testis-expressed protein $33 ;+/+$,

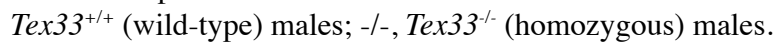

Table II. Fertility analysis of Tex $33^{+/+}$and $T e x 33^{-/-}$mice.

\begin{tabular}{lccc}
\hline Test & Males & Females & Average litter size \\
\hline Male fertility & $+/+(\mathrm{n}=8)$ & $+/+(\mathrm{n}=64)$ & $8.69 \pm 0.37$ \\
& $-/-(\mathrm{n}=8)$ & $+/+(\mathrm{n}=64)$ & $8.41 \pm 0.34$ \\
Female fertility & $+/+(\mathrm{n}=5)$ & $+/+(\mathrm{n}=12)$ & $8.67 \pm 0.86$ \\
& $+/+(\mathrm{n}=5)$ & $-/-(\mathrm{n}=12)$ & $8.92 \pm 0.80$ \\
\hline
\end{tabular}

Data are expressed as mean \pm standard error of the mean and were analyzed using the Student's t-test. Tex33, testis-expressed protein $33 ;+/+$, $\mathrm{Tex}^{+/+}$(wild-type) mice; -/-, Tex33/-/ (homozygous) mice.

Table III. Comparison of pregnancies in $\operatorname{Tex}_{33^{+/+}}$and $\operatorname{Tex} 33^{-/-}$mice.

\begin{tabular}{|c|c|c|c|c|}
\hline Test & Males & Females & Pregnancies (\%) & P-value \\
\hline \multirow[t]{2}{*}{ Male fertility } & $+/+(\mathrm{n}=8)$ & $+/+(n=64)$ & 90.00 & \multirow[t]{2}{*}{0.23} \\
\hline & $-/-(n=8)$ & $+/+(n=64)$ & 94.64 & \\
\hline \multirow[t]{2}{*}{ Female fertility } & $+/+(\mathrm{n}=5)$ & $+/+(n=12)$ & 81.81 & \multirow[t]{2}{*}{0.59} \\
\hline & $+/+(\mathrm{n}=5)$ & $-/-(n=12)$ & 90.00 & \\
\hline
\end{tabular}

Data were analyzed using Chi-square tests. Tex33, testis-expressed protein $33 ;+/+$, Tex33 ${ }^{+/+}$(wild-type) mice; -/-, Tex33/- (homozygous) mice.

fertility, functional analyses were then carried out on Tex33 knockout mice. As shown in Fig. 4A, the sizes of the testes and epididymis were comparable between adult Tex $33^{+/+}$ and Tex33 $3^{-/}$males. The testis-to-body weight ratios were

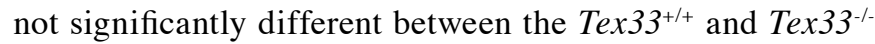
male mice (Fig. 4B). The process of sperm development in the testis was examined by $\mathrm{H} \& \mathrm{E}$ staining. The results revealed that $\mathrm{Te} \times 33^{+/+}$and Tex $33^{-/-}$mice exhibited seminiferous tubules with normal morphology and spermatogenic cells (Fig. 4C).

PAS staining was then performed to analyze the process of acrosome development during spermatogenesis. No apparent morphological differences were observed between the testes of $\mathrm{Te} \times 33^{+/+}$and $\mathrm{Te} \times 33^{-/-}$mice in spermatogenic stages I-XII (Fig. 4D). The morphology of the manchette was evaluated by $\alpha$-tubulin immunofluorescence staining and immunostaining was identified in elongating spermatids in the seminiferous tubules of $T e x 33^{+/+}$and Tex $33^{-/-}$male mice at spermatogenic stage IX (Fig. 4E). H\&E staining revealed the presence of mature sperm in the cauda epididymides of $\mathrm{Te} \times 33^{+/+}$and
Tex33-1- mice (Fig. 4F). In addition, the morphology of sperm exhibited no clear differences between the Tex $33^{+/+}$and Tex33-1- mice (Fig. 4G and Table I). Sperm were counted and their motility assessed to reveal the effect of Tex33 knockout on sperm quality. Sperm counts were determined using a counting board while motility was determined by a CASA analysis that provided total motility and progressive motility data. These investigations revealed no detectable differences in either sperm count or motility between the Tex33 $3^{+/+}$and Tex33 $3^{-/-}$mice (Table I).

A breeding assay was performed to evaluate the fertility of the Tex33 knockout mice. Tex $33^{+/+}$and Tex $33^{-/-}$male mice (10-12 weeks old) were mated separately with female mice

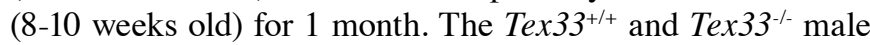
mice exhibited normal fertility (Tables II-IV), and the litter sizes sired by $T e x 33^{-1-}$ mice were similar to those sired by Tex $33^{+/+}$mice (Table II). These results indicate that the fertilizing ability of Tex $33^{-/-}$male mice was not significantly different from that of Tex3 $3^{+/+}$mice. No marked differences in female fertility were observed between the two groups of 
Table IV. Comparison of plugs in $\operatorname{Tex} 33^{+/+}$and $\operatorname{Tex}_{33^{-/-}}$mice.

\begin{tabular}{|c|c|c|c|c|}
\hline Test & Males & Females & Plugs (\%) & P-value \\
\hline Male fertility & $\begin{array}{c}+/+(n=8) \\
-/-(n=8)\end{array}$ & $\begin{array}{l}+/+(n=64) \\
+/+(n=64)\end{array}$ & $\begin{array}{l}93.75 \\
87.50\end{array}$ & 0.35 \\
\hline Female fertility & $\begin{array}{l}+/+(n=5) \\
+/+(n=5)\end{array}$ & $\begin{array}{l}+/+(n=12) \\
-/-(n=12)\end{array}$ & $\begin{array}{l}91.67 \\
83.33\end{array}$ & 0.54 \\
\hline
\end{tabular}

Data were analyzed using Chi-square tests. Tex33, testis-expressed protein $33 ;+/+$, Tex33 $3^{+/+}$(wild-type) mice; -/-, Tex33 $3^{-/-}$(homozygous) mice

mice, as the Tex $33^{-/-}$female mice exhibited normal ovarian structures (Fig. 4H), underwent normal pregnancies and produced equivalent litter sizes to the $T e \times 33^{+/+}$female mice (Tables II and III).

\section{Discussion}

Mature sperm is the end product of spermiogenesis and exhibits highly specialized morphology. Spermiogenesis is facilitated by an important microtubule structure referred to as the manchette, which appears in elongating spermatids and helps to create the shape of the sperm head and transport proteins to the flagellum $(2,11)$. Failure in spermiogenesis, commonly results in subfertility or infertility due to sperm malformation and/or dysfunction $(36,37)$. A number of genes have been reported to be responsible for spermiogenesis (38-42); however, the expression profiles of other genes and their respective roles in spermiogenesis remain unknown and require further investigation. In the present study, Tex33, a gene previously shown to be associated with cilia formation (26), was demonstrated for the first time, to the best of our knowledge, to be testis-specific and associated with spermiogenesis. Its role in spermatogenesis was investigated further using a Tex33 knockout mouse model.

In mammals, primary RNA transcripts give rise to different transcript variants through alternative splicing, thereby resulting in different mRNA and protein isoforms that may have distinct functions and localization patterns (43). Analysis of GenBank data revealed that Tex33 pre-mRNA undergoes alternative splicing to produce three transcripts. Exon 3 is present in V3, but lacking from V1 and V2; this may be due to exon skipping. Similarly, exon skipping may have contributed to the deletion of exons 1 and 2 from V3. In addition, unlike exon 1 of $\mathrm{V} 1$, exon 1 of $\mathrm{V} 2$ has a 75-bp deletion. The results of RT-PCR analysis revealed that all three transcript variants are testis specific. Furthermore, TEX33 protein was also detected only in the testis, indicating that the Tex33 gene is testis specific and conserved from transcription to RNA translation. However, the distribution of this gene in the testis has not previously been elucidated. It has been reported that Tex33 is associated with cilia formation; therefore, we hypothesized that the TEX33 protein may localize on the sperm flagellum. RT-PCR analysis revealed that the expression of Tex33 transcript variants began during spermiogenesis, between days 21 and 28, when round spermatids begin to appear and undergo morphological changes. Consistent with this finding, the expression of TEX33 protein was first detected at day 28, and localized on the acrosome at different developmental stages, including at maturity. Furthermore, it was also detected on the manchette of elongating spermatids during spermatogenesis stages IX and X, as well as on the sperm flagellum. These results confirm that Tex33 is not only associated with cilia, as previously reported, but is also testis-specific and associated with spermiogenesis. Thus, Tex33 may serve a crucial role in mouse spermiogenesis, particularly in terms of acrosome biogenesis, manchette morphology and flagellum formation.

Considering the enrichment and cellular localization of TEX33 in the testis, Tex33 knockout mice were generated by application of the CRISPR/Cas9 system, as reported by Miyata et al (44). The association between TEX33 and spermatid elongation was then explored. Exons 2-4 were selected as targets to ensure the non-functionality of Tex33 after knockout. The deletion was confirmed by genotyping, western blotting and immunofluorescence analysis.

Recent studies have identified that numerous testisenriched/specific genes are necessary for male fertility, including CFAP97 domain containing 1, kinesin family member 9, intraflagellar transporter protein 140 , protease serine 55 and RIKEN cDNA 1700102P08 (39,40,45-47). Mice lacking any of these genes have been shown to be sterile due to a failure to complete spermatogenesis. However, the Tex33 knockout mice were found to be fertile. Further analyses of testis and cauda epididymis histology, acrosome biogenesis, manchette morphology and sperm quality also indicated that there were no significant differences between Tex33 $3^{-1}$ mice and the controls. The possible reason for these knockout mice exhibiting normal spermatogenesis and fertility may be functional redundancy (48-50). Paralogous genes may compensate for the loss of function of knockout genes when they contribute to single function (50). Likewise, it is plausible that Tex33 paralogs, such as Tex11 and Tex14, have compensational functions in the absence of Tex33.

The function of Tex33 during mouse spermatogenesis has been preliminarily clarified using CRISPR/Cas9 system in the present study. However, considering the cellular and subcellular localization of Tex33 on sperm and the acrosome, further investigations using transmission electron microscopy or in vitro fertilization experiments are recommended.

In summary, the present study preliminarily describes the expression profile and role of TEX33 during spermatogenesis in mice. Although Tex33 was testis-specific and associated with spermiogenesis, deletion of this gene had no effect on sperm development and reproduction in mice. This indicates 
that Tex33 may regulate spermiogenesis in association with cooperating factors; however, it is not required for spermiogenesis and male fertility.

\section{Acknowledgements}

Not applicable.

\section{Funding}

The present study was supported by the National Natural Science Foundation of China (grant no. 81871205), the Postgraduate Research \& Practice Innovation Program of Yangzhou University (grant no. XKYCX18_129) and the Undergraduate Science \& Technology Innovation Program of Yangzhou University (grant no. 20180744).

\section{Availability of data and materials}

The datasets used and/or analyzed during the current study are available from the corresponding author on reasonable request.

\section{Authors' contributions}

MX, JX and CN designed and performed the experiments. MX wrote the manuscript. YaZ collected and analyzed the data. MX, TG and YD generated knockout mice and the TEX33 antibody. YiZ designed the study. All authors read and approved the final manuscript.

\section{Ethics approval and consent to participate}

All animal experiments were approved by the Animal Ethics Committee of Yangzhou University.

\section{Patient consent for publication}

Not applicable.

\section{Competing interests}

The authors declare that they have no competing interests.

\section{References}

1. Bao J, Tang C, Li J, Zhang Y, Bhetwal BP, Zheng H and Yan W: RAN-binding protein 9 is involved in alternative splicing and is critical for male germ cell development and male fertility. PLoS Genet 10: e1004825, 2014.

2. Lehti MS and Sironen A: Formation and function of the manchette and flagellum during spermatogenesis. Reproduction 151: R43-R54, 2016.

3. Li RK, Tan JL, Chen LT, Feng JS, Liang WX, Guo XJ, Liu P, Chen Z, Sha JH, Wang YF, et al: Iqcg is essential for sperm flagellum formation in mice. PLoS One 9: e98053, 2014.

4. Nishimura H and L'Hernault SW: Spermatogenesis. Curr Biol 27: R988-R994, 2017.

5. Kazarian E, Son H, Sapao P, Li W, Zhang Z, Strauss JF III and Teves ME: SPAG17 is required for male germ cell differentiation and fertility. Int J Mol Sci 19: 1252, 2018.

6. Bryant JM, Donahue G, Wang X, Meyer-Ficca M, Luense LJ, Weller AH, Bartolomei MS, Blobel GA, Meyer RG, Garcia BA, et al: Characterization of BRD4 during mammalian postmeiotic sperm development. Mol Cell Biol 35: 1433-1448, 2015.
7. Kistler WS, Baas D, Lemeille S, Paschaki M, Seguin-Estevez Q, Barras E, Ma W, Duteyrat JL, Morlé L, Durand B, et al: RFX2 is a major transcriptional regulator of spermiogenesis. PLoS Genet 11: e1005368, 2015

8. Wang H, Wan H, Li X, Liu W, Chen Q, Wang Y, Yang L, Tang H, Zhang X, Duan E, et al: Atg7 is required for acrosome biogenesis during spermatogenesis in mice. Cell Res 24: 852-869, 2014.

9. Liu C, Song Z, Wang L, Yu H, Liu W, Shang Y, Xu Z, Zhao H, Gao F, Wen J, et al: Sirt1 regulates acrosome biogenesis by modulating autophagic flux during spermiogenesis in mice. Development 144: 441-451, 2017.

10. Khawar MB, Gao H and Li W: Mechanism of acrosome biogenesis in mammals. Front Cell Dev Biol 7: 195, 2019.

11. Okuda H, DeBoer K, O'Connor AE, Merriner DJ, Jamsai D and O'Bryan MK: LRGUK1 is part of a multiprotein complex required for manchette function and male fertility. FASEB $\mathrm{J}$ 31: 1141-1152, 2017.

12. Martins LR, Bung RK, Koch S, Richter K, Schwarzmüller L, Terhardt D, Kurtulmus B, Niehrs C, Rouhi A, Lohmann I, et al: Stk33 is required for spermatid differentiation and male fertility in mice. Dev Biol 433: 84-93, 2018.

13. Schultz N, Hamra FK and Garbers DL: A multitude of genes expressed solely in meiotic or postmeiotic spermatogenic cells offers a myriad of contraceptive targets. Proc Natl Acad Sci USA 100: 12201-12206, 2003.

14. Nozawa K, Zhang Q, Miyata H, Devlin DJ, Yu Z, Oura S, Koyano T, Matsuyama M, Ikawa M and Matzuk MM: Knockout of serine-rich single-pass membrane protein 1 (Ssmem1) causes globozoospermia and sterility in male mice. Biol Reprod 103: 244-253, 2020 .

15. Da Costa R, Bordessoules M, Guilleman M, Carmignac V, Lhussiez V, Courot H, Bataille A, Chlémaire A, Bruno C, Fauque $\mathrm{P}$, et al: Vps13b is required for acrosome biogenesis through functions in Golgi dynamic and membrane trafficking. Cell Mol Life Sci 77: 511-529, 2020.

16. Paiardi C, Pasini ME, Gioria M and Berruti G: Failure of acrosome formation and globozoospermia in the wobbler mouse, a Vps54 spontaneous recessive mutant. Spermatogenesis 1: 52-62, 2011.

17. Dunleavy JEM, Okuda H, O'Connor AE, Merriner DJ, O'Donnell L, Jamsai D, Bergmann $\mathrm{M}$ and O'Bryan MK: Katanin-like 2 (KATNAL2) functions in multiple aspects of haploid male germ cell development in the mouse. PLoS Genet 13: e1007078, 2017.

18. Lehti MS, Zhang FP, Kotaja N and Sironen A: SPEF2 functions in microtubule-mediated transport in elongating spermatids to ensure proper male germ cell differentiation. Development 144: 2683-2693, 2017.

19. Schwarz T, Prieler B, Schmid JA, Grzmil P and Neesen J: Ccdc181 is a microtubule-binding protein that interacts with Hook1 in haploid male germ cells and localizes to the sperm tail and motile cilia. Eur J Cell Biol 96: 276-288, 2017.

20. Xu Z, Miyata H, Kaneda Y, Castaneda JM, Lu Y, Morohoshi A, Yu Z, Matzuk MM and Ikawa M: CIB4 is essential for the haploid phase of spermatogenesis in mice. Biol Reprod 103: 235-243, 2020

21. Zhang Z, Kostetskii I, Tang W, Haig-Ladewig L, Sapiro R, Wei Z, Patel AM, Bennett J, Gerton GL, Moss SB, et al: Deficiency of SPAG16L causes male infertility associated with impaired sperm motility. Biol Reprod 74: 751-759, 2006.

22. Zhang Y, Ou Y, Cheng M, Saadi HS, Thundathil JC and van der Hoorn FA: KLC3 is involved in sperm tail midpiece formation and sperm function. Dev Biol 366: 101-110, 2012.

23. Kuo YC, Shen YR, Chen HI, Lin YH, Wang YY, Chen YR, Wang CY and Kuo PL: SEPT12 orchestrates the formation of mammalian sperm annulus by organizing core octameric complexes with other SEPT proteins. J Cell Sci 128: 923-934, 2015.

24. Moretti E, Collodel G, Mazzi L, Russo I and Giurisato E: Ultrastructural study of spermatogenesis in KSR2 deficient mice. Transgenic Res 24: 741-751, 2015.

25. Wang X, Wei Y, Fu G, Li H, Saiyin H, Lin G, Wang Z, Chen S and Yu L: Tssk4 is essential for maintaining the structural integrity of sperm flagellum. Mol Hum Reprod 21: 136-145, 2015.

26. McClintock TS, Glasser CE, Bose SC and Bergman DA: Tissue expression patterns identify mouse cilia genes. Physiol Genomics 32: 198-206, 2008. 
27. Xia M, Xia J, Yang D, Liu M, Niu C, Shen X, Sun H and Zheng Y: Preparation and application of rabbit polyclonal antibody against mouse Tex33. Xi Bao Yu Fen Zi Mian Yi Xue Za Zhi 34: 643-649, 2018 (In Chinese).

28. Busada JT, Velte EK, Serra N, Cook K, Niedenberger BA, Willis WD, Goulding EH, Eddy EM and Geyer CB: Rhox13 is required for a quantitatively normal first wave of spermatogenesis in mice. Reproduction 152: 379-388, 2016.

29. Lee MC and Damjanov I: Lectin binding sites on human sperm and spermatogenic cells. Anat Rec 212: 282-287, 1985.

30. Arya $M$ and Vanha-Perttula T: Comparison of lectin-staining pattern in testis and epididymis of gerbil, guinea pig, mouse, and nutria. Am J Anat 175: 449-469, 1986

31. Wakayama T, Nakata H, Kumchantuek T, Gewaily MS and Iseki S: Identification of 5-bromo-2'-deoxyuridine-labeled cells during mouse spermatogenesis by heat-induced antigen retrieval in lectin staining and immunohistochemistry. J Histochem Cytochem 63: 190-205, 2015.

32. Fàbrega $\mathrm{A}$, Puigmulé $\mathrm{M}$, Dacheux $\mathrm{JL}$, Bonet $\mathrm{S}$ and Pinart $\mathrm{E}$ : Glycocalyx characterisation and glycoprotein expression of Sus domesticus epididymal sperm surface samples. Reprod Fertil Dev 24: 619-630, 2012.

33. Wu Y, Zhong A, Zheng H, Jiang M, Xia Z, Yu J, Chen L and Huang X: Expression of flotilin-2 and acrosome biogenesis are regulated by MiR-124 during spermatogenesis. PLoS One 10 e0136671, 2015.

34. Zhong L, Yang M, Zou X, Du T, Xu H and Sun J: Human umbilical cord multipotent mesenchymal stromal cells alleviate acute ischemia-reperfusion injury of spermatogenic cells via reducing inflammatory response and oxidative stress. Stem Cel Res Ther 11: 294, 2020

35. Huang Q, Liu H, Zeng J, Li W, Zhang S, Zhang L, Song S, Zhou T, Sutovsky M, Sutovsky P, et al: COP9 signalosome complex subunit 5, an IFT20 binding partner, is essential to maintain male germ cell survival and acrosome biogenesis. Biol Reprod 102: 233-247, 2020

36. Anawalt BD: Approach to male infertility and induction of spermatogenesis. J Clin Endocrinol Metab 98: 3532-3542, 2013.

37. García-Vázquez FA, Gadea J, Matás C and Holt WV: Importance of sperm morphology during sperm transport and fertilization in mammals. Asian J Androl 18: 844-850, 2016.

38. Morohoshi A, Miyata H, Shimada K, Nozawa K, Matsumura T, Yanase R, Shiba K, Inaba K and Ikawa M: Nexin-Dynein regulatory complex component DRC7 but not FBXL13 is required for sperm flagellum formation and male fertility in mice. PLoS Genet 16: e1008585, 2020.

39. Oura S, Kazi S, Savolainen A, Nozawa K, Castañeda J, Yu Z Miyata H, Matzuk RM, Hansen JN, Wachten D, et al: Cfap97d1 is important for flagellar axoneme maintenance and male mouse fertility. PLoS Genet 16: e1008954, 2020.
40. Miyata H, Shimada K, Morohoshi A, Oura S, Matsumura T, Xu Z, Oyama Y and Ikawa M: Testis-enriched kinesin KIF9 is important for progressive motility in mouse spermatozoa. FASEB J 34: 5389-5400, 2020.

41. Zhang L, Zhen J, Huang Q, Liu H, Li W, Zhang S, Min J, Li Y, Shi L, Woods J, et al: Mouse spermatogenesis-associated protein 1 (SPATA1), an IFT20 binding partner, is an acrosomal protein. Dev Dyn 249: 543-555, 2020.

42. Lehti MS and Sironen A: Formation and function of sperm tail structures in association with sperm motility defects. Biol Reprod 97: 522-536, 2017.

43. Wang ET, Sandberg R, Luo S, Khrebtukova I, Zhang L, Mayr C, Kingsmore SF, Schroth GP and Burge CB: Alternative isoform regulation in human tissue transcriptomes. Nature 456: 470-476, 2008.

44. Miyata H, Castaneda JM, Fujihara Y, Yu Z, Archambeault DR, Isotani A, Kiyozumi D, Kriseman ML, Mashiko D, Matsumura T, et al: Genome engineering uncovers 54 evolutionarily conserved and testis-enriched genes that are not required for male fertility in mice. Proc Natl Acad Sci USA 113: 7704-7710, 2016.

45. Zhang Y, Liu H, Li W, Zhang Z, Zhang S, Teves ME, Stevens C, Foster JA, Campbell GE, Windle JJ, et al: Intraflagellar transporter protein 140 (IFT140), a component of IFT-A complex, is essential for male fertility and spermiogenesis in mice. Cytoskeleton (Hoboken) 75: 70-84, 2018.

46. Kobayashi K, Endo T, Matsumura T, Lu Y, Yu Z, Matzuk MM and Ikawa M: Prss55 but not Prss51 is required for male fertility in mice. Biol Reprod 103: 223-234, 2020.

47. Wu XL, Yun DM, Gao S, Liang AJ, Duan ZZ, Wang HS, Wang GS and Sun F: The testis-specific gene 1700102P08Rik is essential for male fertility. Mol Reprod Dev 87: 231-240, 2020.

48. Krakauer DC and Plotkin JB: Redundancy, antiredundancy, and the robustness of genomes. Proc Natl Acad Sci USA 99: 1405-1409, 2002.

49. Khan M, Jabeen N, Khan T, Hussain HMJ, Ali A, Khan R, Jiang L, Li T, Tao Q, Zhang X, et al: The evolutionarily conserved genes: Tex37, Ccdc73, Prss55 and Nxt2 are dispensable for fertility in mice. Sci Rep 8: 4975, 2018.

50. Holcomb RJ, Oura S, Nozawa K, Kent K, Yu Z, Robertson MJ, Coarfa C, Matzuk MM, Ikawa M and Garcia TX: The testisspecific serine proteases PRSS44, PRSS46, and PRSS54 are dispensable for male mouse fertility. Biol Reprod 102: 84-91, 2020.

This work is licensed under a Creative Commons Attribution-NonCommercial-NoDerivatives 4.0 International (CC BY-NC-ND 4.0) License. 